\title{
Comparison of erythrocyte indices to differentiate between iron deficiency and alpha-thalassaemias in children with microcytosis and/or hypochromia
}

H. Narchil and R.B. Basak ${ }^{2}$

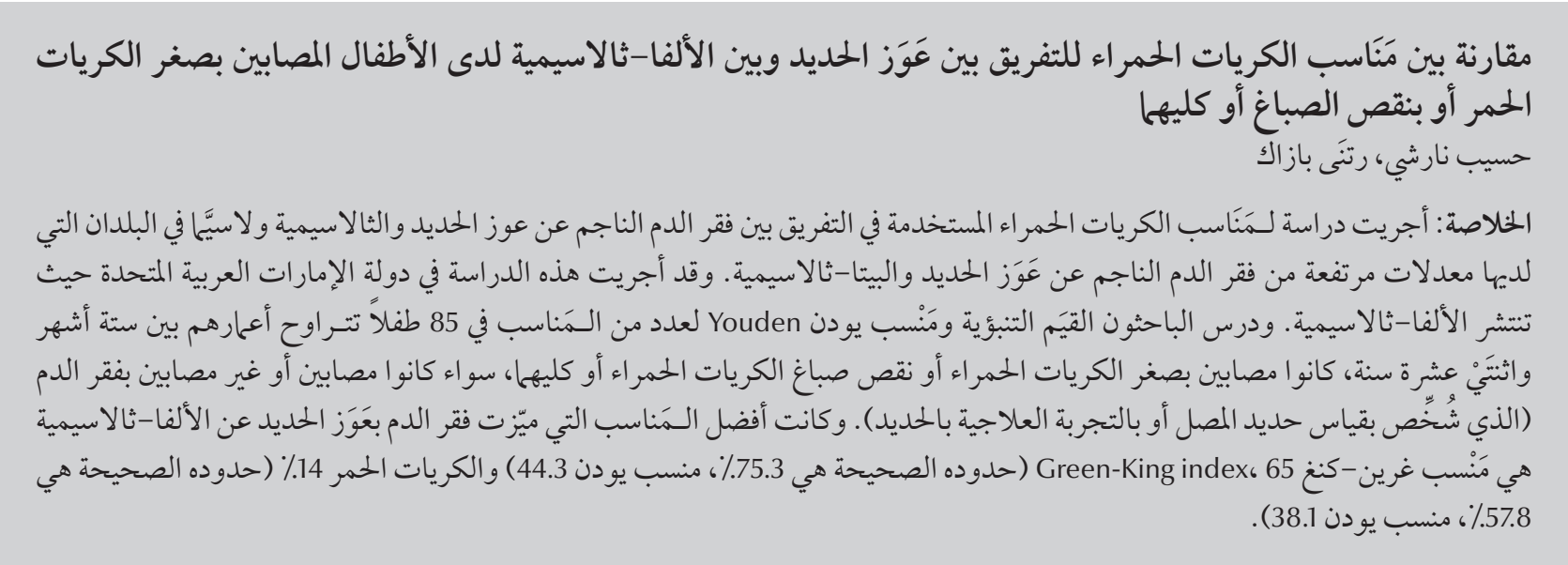

ABSTRACT Erythrocyte indices used to differentiate between iron deficiency anaemia (IDA) and thalassaemias have been studied mainly in countries with a high prevalence of IDA or beta-thalassaemias. This study was carried out in the United Arab Emirates where alpha-thalassaemias are prevalent. We studied the predictive value and Youden index of several indices in 85 children aged 6 months to 12 years with microcytosis and/or hypochromia, with or without anaemia (determined by serum measurement of iron or therapeutic iron trial). The best discriminatory indices for detecting IDA versus alpha-thalassaemias were a Green-King index $>65$ (correctly identified $75.3 \%$ of children, Youden index 44.3) and red cell distribution width $>14 \%$ (correctly identified $57.8 \%$, Youden index 38.1).

Comparaison des indices érythrocytaires en vue de distinguer les carences en fer des alpha-thalassémies chez les enfants présentant une microcytose et/ou une hypochromie

RÉSUMÉ L'utilisation des indices érythrocytaires pour distinguer les anémies ferriprives des thalassémies a été principalement étudiée dans les pays présentant une forte prévalence d'anémie ferriprive ou de bêtathalassémies. Cette étude a été réalisée aux Émirats arabes unis où les alpha-thalassémies sont répandues. Nous avons étudié la valeur prédictive et l'indice de Youden de plusieurs indices chez 85 enfants âgés de six mois à 12 ans, présentant une microcytose et/ou une hypochromie, avec ou sans anémie (déterminée par la mesure sérique du fer ou l'essai thérapeutique du fer). Les meilleurs indices discriminatoires pour le dépistage de l'anémie ferriprive et des alpha-thalassémies et la distinction entre ces deux affections sont un indice de Green-King supérieur à 65 (75,3\% des enfants correctement dépistés, indice de Youden de 44,3) et un indice de distribution érythrocytaire supérieur à $14 \%$ (57,8 \% des enfants correctement dépistés, indice de Youden de $38,1)$.

'Department of Paediatrics, Faculty of Medicine and Health Sciences, Al Ain, United Arab Emirates (Correspondence to H. Narchi: hassib.narchi@ uaeu.ac.ae).

${ }^{2}$ Department of Paediatrics, Al Ain Hospital, Al Ain, United Arab Emirates.

Received: 21/01/09; accepted: 17/03/09 


\section{Introduction}

In the United Arab Emirates (UAE) the prevalence of anaemia in children is high $(36.1 \%)$, primarily caused by iron depletion (36.0\%) and beta-thalassaemia $(8.7 \%)$ and in the majority of the rest by alpha-thalassaemias (AT) [1-3]. As hypochromia and microcytosis are almost universally present in this heterogeneous group and cannot differentiate between these conditions, several computational indices have been proposed, using the readily available erythrocyte results in a routine blood count [4]. These include the red blood cell distribution width (RDW), the RDW index, the Mentzer index, the Green and King index, the England and Fraser index, the Shine and Lal index and the Srivastava index (described later).

All these formulae have been tested with different cut-off values but none has been found to be sufficiently specific or sensitive to obviate the need for confirmation of the diagnosis. Confirmatory tests require additional blood sampling from these children and incur non-negligible costs $[5,6]$ and a significant number of false-negative results for the detection of beta-thalassaemia trait occur with these indices [7]. In addition, most of these studies have been carried out in adults and in countries with a high prevalence of either iron deficiency anaemia (IDA) or beta-thalassaemia haemoglobinopathies.

For any investigation with a known sensitivity and specificity, the predictive value (positive or negative) varies according to the prevalence of the condition in a particular population. In the UAE, AT trait is much more common (28\%-56\%) than beta-thalassaemia trait $(8.7 \%)[8,9]$. We therefore evaluated these erythrocyte indices (with the cut-off values defined in the literature) to differentiate between IDA and AT haemoglobinopathies in our population. A good discriminating index would allow a selective diagnostic approach in children with hypochromia and/or microcytosis in our population, with potentially important cost savings as well as a reduced need for blood sampling. In addition, a high likelihood of haemoglobinopathy based on the indices would alert physicians to the risks of empirical iron therapeutic treatment in a child more likely to have thalassaemia.

\section{Methods}

This was a retrospective cohort study of children with microcytosis, with or without anaemia, managed in the paediatric department of a large general hospital in the United Arab Emirates, over a 4-month period from 1 February 2008 to 30 May 2008.

\section{Sample}

Based on the published incidence of hypochromic microcytic anaemia of $35 \%$ in the paediatric population in the UAE (regardless of the cause), a minimum sample size of 85 was needed to have a 5\% significance level, $10 \%$ precision and $95 \%$ confidence to detect these abnormal indices (Epi-Info statistical software, version 6.04).

The log book in the haematology laboratory of our hospital was reviewed to identify all children between the ages of 6 months and 12 years who were diagnosed over the study period with microcytosis and/or hypochromia, with or without anaemia. The criteria for microcytosis were mean corpuscular volume $(\mathrm{MCV})<70 \mathrm{fL}$ in children aged $<2$ years, $<75 \mathrm{fL}$ for ages 2-6 years and $<77 \mathrm{fL}$ at any other age. Criteria for hypochromia were mean cell haemoglobin concentration $(\mathrm{MCH})$ $<30 \mathrm{~g} / \mathrm{dL}$ at age $<2$ years and $<31 \mathrm{~g} /$ $\mathrm{dL}$ at any other age. Criteria for anaemia were haemoglobin $(\mathrm{Hb})<10.5$ $\mathrm{g} / \mathrm{dL}$ at age $<2$ years and $<11.5 \mathrm{~g} / \mathrm{dL}$ otherwise.

The exclusion criteria were: children aged $<6$ months (in view of a low prevalence of IDA and of haematological findings of thalassaemia); those already diagnosed prior to the study with beta-thalassaemia, sickle-cell anaemia, another haemoglobinopathy, iron deficiency or lead intoxication; those already on iron therapy or transfused over the previous 4 months (regardless of the cause); those with a known alternative diagnosis (e.g. aplastic anaemia, haematological malignancy); those with haemoglobinopathies other than AT (e.g. beta-thalassaemias, sickle-cell anaemias) as the focus of the study was IDA versus AT; those whose investigations for iron deficiency or for haemoglobinopathy were not performed or were not available for review; and those with haemoglobinopathies with a coexistent iron deficiency, to avoid a "contamination" effect in interpreting the results.

Approval was granted and patient consent was waived (as this was a retrospective case-notes study) by the institutional ethics review committee (Medical District Human Research Ethics Committee protocol 07/127).

\section{Data collection}

This study was a retrospective casenotes review of the results of investigations already performed by the treating physician on the children identified from the laboratory log book. These included complete red blood cell count (RBC), $\mathrm{Hb}, \mathrm{MCV}, \mathrm{MCH}$ and RDW levels obtained with a Coulter Counter STKS (Coulter), serum iron and serum iron binding capacity (TIBC) determined calorimetrically, ferritin by an automated enzyme-linked fluorescent assay (Vidas Ferritin, bioMérieuxVitek) and high-performance liquid chromatography analysis for haemoglobinopathies (Biorad Variant). The remaining discrimination erythrocyte indices were calculated using the red blood cell indices as defined in Table 1.

The data collected and analysed included: age, sex, erythrocyte indices values, results of investigations for iron deficiency and haemoglobinopathy and 


\begin{tabular}{lcc}
\hline \multicolumn{1}{l}{ Table 1 Cut-offs used for the different indices in this study } & \\
\hline Index & Calculation & Cut-off value \\
Mentzer index & $\mathrm{MCV} / \mathrm{RBC}$ & 13 \\
Green-King formula & $\mathrm{MCV}^{2} \times \mathrm{RDW} /(\mathrm{Hb} \times 100)$ & 65 \\
England-Fraser formula & $\mathrm{MCV}-(5 \times \mathrm{Hb})+\mathrm{RBC}+3.4$ & 0 \\
Shine-Lal formula & $\mathrm{MCV} \times \mathrm{MCH} / 100$ & 1530 \\
Srivastava formula & $\mathrm{MCH} / \mathrm{RBC}$ & 4.4 \\
RDW index & $\mathrm{MCV} \times \mathrm{RDW} / \mathrm{RBC}$ & 220 \\
\hline
\end{tabular}

$M C V=$ mean cell volume; $R B C=$ red blood cell count $H b=$ haemoglobin; $M C H=$ mean cell haemoglobin; $R D W=$ red cell distribution width

response to a therapeutic iron trial when applicable.

The outcome was the confirmation of either iron deficiency (serum ferritin $<10 \mathrm{ng} / \mathrm{mL}$, serum iron $<50 \mu \mathrm{g} / \mathrm{dL}$, $\mathrm{TIBC}<250 \mu \mathrm{g} / \mathrm{dL}$ or correction byiron therapy) or AT haemoglobinopathy. As no DNA testing was available for the diagnosis of AT trait, this was diagnosed when $\mathrm{Hb}$ electrophoresis was normal, without any elevation of fetal haemoglobin or haemoglobinalpha 2, with no iron deficiency but with a family history suggestive of asymptomatic chronic microcytosis without iron deficiency.

For the calculated erythrocyte indices, we used the cut-off values commonly described in the literature to study their sensitivity, specificity, correlation and positive predictive value for the diagnosis of IDA versus AT.

\section{Analysis}

The chi-squared test (or Fisher exact test for small numbers) was used for the study of univariate associations between each index and the outcome. Continuous variables were compared with the Student 2 -sample $t$-test. For each index, we calculated its specificity, sensitivity and positive and negative predictive value for IDA, as well as the proportion of IDA it correctly identified, using the statistical package Stata, version 8. For all calculations, statistical significance was defined as $P$-value $<0.05$.

We also calculated the Youden index (sensitivity + specificity -100$)$ for each of these indices to diagnose IDA, which, by taking into account both sensitivity and specificity, measures their validity to diagnose IDA versus AT. A high Youden value for a test makes it a reliable discrimination index for that purpose.

\section{Results}

\section{Clinical descriptive data}

A total of 85 children ( $50.6 \%$ females) were included in the study. The mean age was 5.9 years (range $0.5-15$ years). The majority were of Emirati nationality (75.4\%), with a small proportion from the Indian subcontinent (5.0\%) and the remainder from diverse Middle Eastern countries.

Iron deficiency was the cause of microcytosis and/or hypochromia in 18 children (21.2\%). It was diagnosed by serum measurement of iron in 13 (72.0\%) and by therapeutic iron trial in the remainder. All other 67 children (78.8\%) had AT trait.

\section{Haematological data and calculated indices}

The mean and standard deviation (SD) values obtained from the full blood count in the whole sample were: RBC $5.2\left(\mathrm{SD} \mathrm{0.6)} \times 10^{12} / \mathrm{L}, \mathrm{Hb} 10.5(\mathrm{SD}\right.$ $1.9) \mathrm{g} / \mathrm{dL}, \mathrm{MCV} 64$ (SD 7.5) fL, MCH 20.4 (SD 3.0) pg, MCHC 30.4 (SD 2.3) g/dL and RDW $16.3 \%$ (SD 4.2)\%.

These values and the calculated indices were compared between children with IDA and those with haemoglobinopathies (Table 2). There was a statistically significant difference between the
2 groups in all parameters except for the MCH, RDW index, Mentzer index, $\mathrm{MCH} / \mathrm{RBC}$ ratio and Srivastava index.

When we analysed these indices using published cut-off values, all of them discriminated very well between the 2 groups, except for the Srivastava index $>4.4$, the RDW index $>220$, and the Shine-Lal index $<1530$ (Table 3).

The calculated sensitivity, specifcity and positive and negative likelihood ratios for these tests to diagnose IDA versus AT are shown in Table 4 . The calculated Youden index shows that the best discriminatory indices, in descending order were: Green-King index $>65$, RDW $>14 \%$, England-Fraser index $>0$, $\mathrm{RDW} / \mathrm{RBC}$ ratio $>3.3$ and Srivastava index $>4.4$.

\section{Discussion}

Differentiating between the causes of microcytosis and hypochromia in children is important. Not only does an appropriate diagnosis allow adequate management and appropriate family counselling (in case of haemoglobinopathy) and have important prognostic implications, but it also prevents unnecessary iron therapy (as a therapeutic trial for presumed IDA) for children with haemoglobinopathies who are already at increased risk of iron toxicity.

Although obtaining a detailed family and nutritional history and history of blood loss are part of the diagnostic process in such children, haematological parameters are often measured to confirm the etiology. If not diagnosed in the early neonatal period by the presence of Bart haemoglobin, the diagnosis of AT in childhood requires DNA analysis, which is not widely available.

The routine blood count is widely available and inexpensive to perform. In conjunction with microcytosis, different erythrocyte indices have been used with variable success to differentiate between IDA and haemoglobinopathies [4]. None is entirely satisfactory in 


\begin{tabular}{|c|c|c|c|}
\hline \multirow[t]{2}{*}{ Variable } & Iron deficiency anaemia $(n=18)$ & Alpha-thalassaemias $(n=67)$ & $\boldsymbol{P}$-value \\
\hline & Mean (SD) & Mean (SD) & \\
\hline RBC count $\left(10^{12} / \mathrm{L}\right)$ & $4.8(0.7)$ & $5.3(0.5)$ & $<0.001$ \\
\hline $\mathrm{Hb}(\mathrm{g} / \mathrm{dL})$ & $8.6(2.7)$ & $11.0(1.3)$ & $<0.001$ \\
\hline MCV (fL) & $60.6(9.5)$ & $65.0(6.6)$ & 0.03 \\
\hline $\mathrm{MCH}(p g)$ & $19.2(4.2)$ & $20.7(2.6)$ & 0.06 \\
\hline $\mathrm{MCHC}(\mathrm{g} / \mathrm{dL})$ & $29.2(2.7)$ & $31.3(1.4)$ & 0.02 \\
\hline RDW (\%) & $19.2(4.2)$ & 15.5 (3.9) & $<0.001$ \\
\hline RDW index & $224.8(69.4)$ & $202.9(91.4)$ & 0.3 \\
\hline Mentzer index & $11.5(2.4)$ & $12.4(3.2)$ & 0.2 \\
\hline England-Fraser index & $8.1(8.9)$ & $0.5(14.2)$ & 0.03 \\
\hline Shine-Lal index & $630.3(314.8)$ & 927.3 (316.8) & $<0.001$ \\
\hline $\mathrm{MCV} / \mathrm{MCH}$ ratio & $3.3(0.48)$ & $3.0(0.50)$ & 0.03 \\
\hline $\mathrm{MCH} / \mathrm{RBC}$ ratio & $11.5(2.4)$ & $12.5(3.2)$ & 0.2 \\
\hline RDW/RBC ratio & $4.0(1.3)$ & $3.2(1.3)$ & 0.02 \\
\hline Green-King index & $84.2(34.2)$ & $62.5(31.4)$ & 0.01 \\
\hline Srivastava index & $4.0(1.0)$ & $4.2(2.2)$ & 0.8 \\
\hline
\end{tabular}

$S D=$ standard deviation; $R B C=$ red blood cell count; $H b=$ haemoglobin $; M C V=$ mean cell volume; $M C H=$ mean cell haemoglobin; $M C H C=$ mean cell haemoglobin concentration; $R D W=$ red cell distribution width.

that aspect [5-7]. Most of these studies have been carried out in populations with either a low risk of haemoglobinopathies (such as in some industrialized countries) or a high prevalence of betathalassaemia haemoglobinopathies (in developing countries) [10-13]. As with any investigation with a known sensitivity and specificity, the predictive value (positive or negative) varies according to the prevalence of the condition in a particular population, and it is important to validate the value of these indices in a population such as ours where there is a high incidence of AT haemoglobinopathies. Because the focus of this study was to differentiate IDA from AT haemoglobinopathy, we deliberately excluded children with haemoglobinopathies who had a coexistent iron deficiency, in order to avoid a "contamination" effect in interpreting the results. We cannot therefore comment on the value of these indices or extrapolate the study findings to children who have such a combination.

An ideal screening test would have a sensitivity of $100 \%$ with a specificity of
$100 \%$, while a totally useless one would have $0 \%$ sensitivity and specificity. In reality, each test has an intermediate value for sensitivity and for specificity, with a high value for one being often associated with a lower value for the other measurement. A test with a very high sensitivity is desirable to diagnose conditions we do not wish to miss, while a test with a high specificity is required when expensive or invasive confirmatory investigations are required for positive cases. For the current study, neither of these requirements was a necessity;

\begin{tabular}{|c|c|c|c|c|c|}
\hline \multirow{2}{*}{ Index and cut-off } & \multicolumn{2}{|c|}{ Iron deficiency anaemia $(n=18)$} & \multicolumn{2}{|c|}{ Alpha-thalassaemias $(n=67)$} & \multirow{2}{*}{$P$-value } \\
\hline & No. of patients & $\%$ & No. of patients & $\%$ & \\
\hline Mentzer index $>13$ & 5 & 27.8 & 37 & 56.0 & 0.03 \\
\hline Srivastava index $>4.4$ & 8 & 47.0 & 14 & 23.7 & 0.06 \\
\hline RDW index > 220 & 6 & 33.3 & 21 & 31.3 & 0.8 \\
\hline England-Fraser index $>0$ & 17 & 94.4 & 45 & 67.1 & 0.02 \\
\hline RDW $>14 \%$ & 16 & 88.9 & 33 & 50.8 & 0.004 \\
\hline $\mathrm{RBC}>5 \times 10^{12} / \mathrm{L}$ & 6 & 33.3 & 50 & 79.4 & $<0.001$ \\
\hline RDW/RBC ratio $>3.3$ & 11 & 61.1 & 23 & 34.3 & 0.04 \\
\hline Green-King index $>65$ & 12 & 66.7 & 15 & 22.4 & $<0.001$ \\
\hline Shine-Lal index $<1530$ & 18 & 100.0 & 64 & 95.5 & 0.3 \\
\hline
\end{tabular}

$R B C=$ red blood cell count; $R D W=$ red blood cell distribution width . 


\begin{tabular}{|c|c|c|c|c|c|c|}
\hline Index and cut-off & $\begin{array}{c}\text { Sensitivity } \\
(\%)\end{array}$ & $\begin{array}{c}\text { Specificity } \\
(\%)\end{array}$ & LR (+ve test) & LR (-ve test) & $\begin{array}{l}\% \text { correctly } \\
\text { classified }\end{array}$ & $\begin{array}{c}\text { Youden } \\
\text { index }\end{array}$ \\
\hline Green-King index $>65$ & 66.7 & 77.6 & 2.9 & 0.4 & 75.3 & 44.3 \\
\hline RDW $>14 \%$ & 88.9 & 49.2 & 1.7 & 0.2 & 57.8 & 38.1 \\
\hline England-Fraser index $>0$ & 94.4 & 32.8 & 1.4 & 0.1 & 45.8 & 27.2 \\
\hline $\mathrm{RDW} / \mathrm{RBC}$ ratio $>3.3$ & 61.1 & 65.7 & 1.7 & 0.6 & 64.7 & 26.8 \\
\hline Srivastava index $>4.4$ & 47.6 & 76.2 & 1.9 & 0.7 & 69.7 & 23.8 \\
\hline RDW index $>220$ & 33.3 & 68.6 & 1.0 & 0.9 & 61.2 & 1.9 \\
\hline Shine-Lal index $<1530$ & 0.0 & 95.5 & 0.0 & 1.0 & 75.3 & -4.5 \\
\hline Mentzer index $>13$ & 27.8 & 43.9 & 0.5 & 1.6 & 40.5 & -28.3 \\
\hline $\mathrm{RBC}>5 \times 10^{12} / \mathrm{L}$ & 33.3 & 20.6 & 0.4 & 3.2 & 23.4 & -46.1 \\
\hline
\end{tabular}

$R B C=$ red blood cell count; $R D W=$ red blood cell distribution width; $L R=$ likelihood ratio.

wewere only interested in investigations with the combined maximum values for sensitivity and specificity, as they correctly identify the highest proportion of children evaluated. The Youden index takes into account both the sensitivity and specificity of a test and correlates positively with the proportion of children correctly diagnosed by that test $[14,15]$. Using the Youden index, we found that a Green-King index $>65$ (which correctly identified $75.3 \%$ of children) and a RDW > 14\% (which correctly identified $57.8 \%$ of children) were the best indices to differentiate between IDA and AT.
A previous study, from Turkey, looked at the value of erythrocyte indices to differentiate between IDA and beta-thalassaemia trait, and also used the Youden index [16]. Contrary to our results, they found that RBC count and RDW were the most discriminatory for that purpose. The differences can be explained by the difference in study design. Beta-thalassaemia trait was the only haemoglobinopathy they tested for (constituting $41 \%$ of all cases with microcytosis) and the prevalence of IDA was $58.7 \%$. By contrast, in our study, the prevalence of IDA was much lower $(21.2 \%)$ and the prevalence of haemoglobinopathies much higher
(78.8\%), confirming previous studies in our population. [1-3]. In addition, unlike the study from Turkey where children with haemoglobin level $<8.7$ $\mathrm{g} / \mathrm{dL}$ were excluded, we did not use a specific haemoglobin level as a threshold for exclusion.

\section{Conclusions}

In our population with a high prevalence of AT haemoglobinopathies, a GreenKing index $>65$ and a RDW $>14 \%$ were the best indices to diagnose IDA versus AT in children with microcytosis and/ or hypochromia.

\section{References}

1. Miller $\mathrm{CJ}$ et al. Factors associated with iron depletion and iron deficiency anemia among Arabic preschool children of the United Arab Emirates. Saudi Medical Journal, 2004, 25:843-847.

2. Miller CJ et al. A hematological survey of preschool children of the United Arab Emirates. Saudi Medical Journal, 2003, 24:609-613.

3. Hossain MM et al. The prevalence and correlates of anaemia among young children and women of childbearing age in $\mathrm{Al}$ Ain, United Arab Emirates. Annals of Tropical Paediatrics, 1995, 15:227-235.

4. D'Onofrio G et al. Automated measurement of red blood cel microcytosis and hypochromia in iron deficiency and betathalassemia trait. Archives of Pathology \& Laboratory Medicine, 1992, 116:84-89.

5. Beyan C, Kaptan K, Ifran A. Predictive value of discrimination indices in differential diagnosis of iron deficiency anemia and beta-thalassemia trait. European Journal of Haematology, 2007, 78:524-526.
6. Marsh WL Jr, Bishop JW, Darcy TP. Evaluation of red cell volume distribution width (RDW). Hematologic Pathology, 1987, 1:117-123.

7. Ntaios $\mathrm{G}$ et al. Discrimination indices as screening tests for betathalassemic trait. Annals of Haematology, 2007, 86:487-491.

8. El-Hazmy MAF, Warsy AS. Hemoglobinopathies in Arab countries. In: Teebi AS, ed. Genetic disorders among Arab populations. New York, Oxford University Press, 1997:83-110.

9. El-Kalla S, Baysal E. Alpha-thalassemia in the United Arab Emirates. Acta Haematological, 1998, 100:49-53.

10. McClung JP et al. Prevalence of iron deficiency and iron deficiency anemia among three populations of female military personnel in the US army. Journal of the American College of Nutrition, 2006, 25:64-69.

11. Aslan D et al. Importance of RDW value in differential diagnosis of hypochrome anemias. American Journal of Haematology, 2002, 69:31-33.

12. Rathod DA et al. Usefulness of cell counter-based parameters and formulas in detection of beta-thalassemia trait in areas of 
high prevalence. American Journal of Clinical Pathology, 2007, 128:585-589.

13. Baqar MS, Khurshid M, Molla A. Does red blood cell distribution width (RDW) improve evaluation of microcytic anaemias? Journal of the Pakistan Medical Association, 1993, 43:149-151.

14. Pekkanen J, Pearce N. Defining asthma in epidemiological studies. 2 European Respiratory Journal, 1999, 14:951-957.
15. Burney PG et al. What symptoms predict the bronchial response to histamine? Evaluation in a community survey of the bronchial symptoms questionnaire (1984) of the International Union Against Tuberculosis and Lung Disease. International Journal of Epidemiology, 1989, 18:165-173.

16. Demir A et al. Most reliable indices in differentiation between thalassemia trait and iron deficiency anemia. Pediatrics International, 2002, 44:612-616.

\section{Thalassaemias}

The alpha and beta thalassaemias are the most common inherited single-gene disorders in the world with the highest prevalence in areas where malaria was or still is endemic. The burden of this disorder in many regions is of such a magnitude that it represents a major public health concern. For example in the Islamic Republic of Iran, it is estimated that about 8000 pregnancies are at risk each year. In some endemic countries in the Mediterranean region, longestablished control programmes have achieved $80 \%-100 \%$ prevention of newly affected births.

Early treatment of thalessaemia has proved to be very effective in improving the quality of life of patients. Currently, genetic testing and counselling, and prenatal diagnosis play an increasingly important role in informing individual as well as professional decisions around the prevention, management and treatment of this disease.

Source: http://www.who.int/genomics/public/geneticdiseases/en/index2.html 